\title{
APLIKASI E-BUDGETING DANA PROMOSI (STUDI KASUS : DIVISI MARKETING PERGURUAN TINGGI RAHARJA)
}

\author{
Dede Cahyadi ${ }^{1}$ \\ Euis Siti Nur Aisyah ${ }^{2}$ \\ Imami Fatimatun ${ }^{3}$ \\ 1,2,3 AMIK Raharja Informatika - Prodi Komputerisasi Akuntansi \\ e-mail:_dede.cahyadi@raharja.info,euis@raharja.info,imami.fatimatun@raharja.info
}

\begin{abstract}
ABSTRAK
Pemerintah telah menargetkan paling lambat pada tahun 2017 akan menerapkan $e$ budgeting sebagai salah satu bagian dari penerapan e-government di pemerintah pusat dan daerah. Di beberapa daerah di Indonesia terbukti bahwa penerapan e-budgeting dapat meningkatkan efektivitas dan efisiensi dalam penggunaan anggaran, dapat mempercepat realisasi anggaran juga terwujudnya transparansi. Mewujudkan smart city di setiap daerah di Indonesia memerlukan penerapan teknologi informasi yang baik agar konsepnya dapat diimplementasikan. Perguruan Tinggi Raharja sebagai Perguruan Tinggi di bidang teknologi informasi menyambut baik dan turut berperan dalam mewujudkan konsep smart city di Kota Tangerang, salah satunya sebagai prototipe dirancang sebuah aplikasi e-budgeting dana promosi dengan studi kasus divisi marketing di Perguruan Tinggi Raharja untuk mengetahui penyerapan anggaran yang telah digunakan oleh divisi marketing. Aplikasi ini dirancang berbasis web menggunakan metode berorientasi objek dengan toolset diagram UML. Hasil dari penelitian ini adalah suatu aplikasi $e$-budgeting untuk mengelola anggaran dana promosi agar lebih efektif, efisien dan transparan.
\end{abstract}

Kata kunci: E-Budgeting, Anggara Dana Promosi

\section{ABSTRACT}

The government has targeted by 2017 to implement e-budgeting as part of e-government implementation in central and local government. In some regions in Indonesia it is evident that the implementation of e-budgeting can increase the effectiveness and efficiency in the use of the budget, can accelerate the realization of the budget as well as the realization of transparency. Creating smart city in every region in Indonesia requires good information technology so that the concept can be implemented. Raharja College as a university in the field of information technology welcomes and contributes in realizing the concept of smart city in Tangerang City, one of them as an e-budgeting application for promotional fund with case study marketing division in Raharja College to find out the budget absorption has been used by the marketing division. This application is designed web-based using object-oriented method with toolset UML diagram. The result of this research is an e-budgeting application to manage the promotion fund budget to be more effective, efficient and transparent.

Kata kunci: E-Budgeting, the promotion fund budget

\section{Pendahuluan}

Pemerintah telah menargetkan paling lambat pada tahun 2017 akan menerapkan $e$ budgeting di seluruh instansi pemerintahan, sebagai salah satu bagian dari penerapan $e$ government di pemerintah pusat dan daerah. Di beberapa daerah di Indonesia terbukti bahwa penerapan e-budgeting dapat meningkatkan efektivitas dan efisiensi dalam penggunaan anggaran, dapat mempercepat realisasi anggaran juga terwujudnya transparansi.

Mewujudkan smart city di setiap daerah di Indonesia memerlukan penerapan

Vol.3 No.2 - Agustus 2017 
teknologi informasi yang baik agar konsepnya dapat diimplementasikan. Perguruan Tinggi Raharja sebagai Perguruan Tinggi di bidang teknologi informasi menyambut baik dan turut berperan dalam mewujudkan konsep smart city di Kota Tangerang.

Penelitian ini membahas lingkup yang lebih kecil yaitu merancang aplikasi $e$ budgeting dana promosi dengan studi kasus divisi marketing di Perguruan Tinggi Raharja sebagai suatu prototipe. Keberadaan divisi marketing di Perguruan Tinggi Raharja sangatlah penting karena perannya untuk mempromosikan kampus kepada masyarakat luas, serta memberi pelayanan yang prima kepada para mahasiswa. Sistem penganggaran divisi marketing saat ini sudah berjalan secara rutin, setiap akhir tahun divisi marketing menyelenggarakan kegiatan rapat kerja tahunan untuk mengevaluasi pencapaian target dan laporan penggunaan anggaran dana promosi dalam satu tahun yang sudah berjalan, serta menetapkan rencana kerja dan anggaran dana promosi yang ditetapkan untuk satu tahun kedepan.

Identifikasi permasalahan yang ditemui pada sistem penganggaran dana promosi adalah belum efektif dan efisien, pencatatan anggaran dana promosi menggunakan aplikasi microsoft excel yang diinput secara periodik, sehingga laporan penggunaan anggaran dana promosi tidak dapat diketahui secara real time dan online. Oleh karena itu penelitian ini akan merancang sebuah prototipe aplikasi e-budgeting yang digunakan untuk mengolah anggaran dana promosi pada divisi marketing Perguruan Tinggi Raharja agar lebih efektif, efisien dan transparan. Berdasarkan latar belakang diatas, maka dirumuskan permasalahan sebagai berikut: "Bagaimana rancangan prototipe aplikasi e-budgeting untuk mengelola anggaran dana promosi pada divisi marketing Perguruan Tinggi Raharja?"

\section{Tinjauan Pustaka}

\subsection{E-Budgeting}

Konsep e-budgeting merupakan pengembangan konsep budgeting, salah satu financial tools di dalam mengelola suatu perusahaan maupun pemerintah. [1]

Budget merupakan alat perencanaan keuangan dari dua sisi yaitu perkiraan penerimaan dan perkiraan pengeluaran. Budget pengeluaran dibuat berdasarkan keperluan dari suatu bagian organisasi supaya bisa berjalan sesuai dengan target yang di tentukan. Di dalam membuat budget, selalu memasukkan jumlah/volume barang dan jasa yang di rencanakan, serta harga satuan, beserta uraian singkat pengeluaran.

Fungsi budget yang utama adalah perencanaan keuangan, yang mencerminkan tujuan/sasaran/objective yang akan dicapai dan sudah memperoleh persetujuan dari level lebih atas. Beberapa manfaat e-budgeting adalah: [2]

1. Kontrol akan lebih mudah dilakukan.

2. Kontrol dapat dilakukan sejak pertama tahap perencanaan.

3. Transparansi anggaran dapat dilakukan.

\subsection{Literature Review}

Penelitian yang dilakukan oleh Nugroho dan Wuryandari membahas tentang pengembangan e-budgeting dalam tata kelola Pemerintahan Daerah. Rancangan aplikasi perangkat lunak sistem anggaran elektronik e-Budgeting merupakan bagian dari eGovernment, dirancang berbasis web, pengembangannya menggunakan bahasa pemrograman Web, yaitu PHP dengan basis data MySQL. Penerapan e-Budgeting dalam tata pemerintahan daerah akan mendukung keputusan manajerial dalam penyusunan Anggaran Belanja dan Pendapatan Daerah (APBD). [3]

Penelitian yang dilakukan oleh Fanida dan Niswah membahas tentang Government 
Resource Management System (GRMS) merupakan inovasi layanan publik dalam pengelolaan keuangan daerah di Pemerintah Kota Surabaya. GRMS yang diterapkan memiliki 6 segmen segmen yang memiliki kegiatan pengelolaan keuangan yang terintegrasi, yaitu E-Budgeting, E-Project Planning, E-Procurement, E-Delivery, EControlling, E-Performance. [4]

Penelitian yang dilakukan oleh Saadah membahas tentang akuntabilitas dan transparansi anggaran melalui E-Government (studi tentang penganggaran di Pemerintahan Daerah Kabupaten Blitar), akuntabilitas dan transparansi anggaran yang dilakukan oleh Kabupaten Blitar sudah dilaksanakan dengan baik, namun proses penganggaran secara manual masih rawan terjadinya penyimpangan anggaran. [5]

Berdasarkan review yang telah dilakukan terhadap beberapa penelitian sebelumnya, maka kesimpulannya e-budgeting telah diterapkan terhadap sebagian pemerintah daerah, namun e-budgeting masih jarang diterapkan terhadap institusi diluar pemerintahan.

\section{Metode Penelitian}

Rancangan prototipe aplikasi e-budgeting ini dilakukan melalui metode tahapan rekayasa perangkat lunak, mulai dari tahap analisis, tahap rancangan sistem, hingga tahap implementasi.

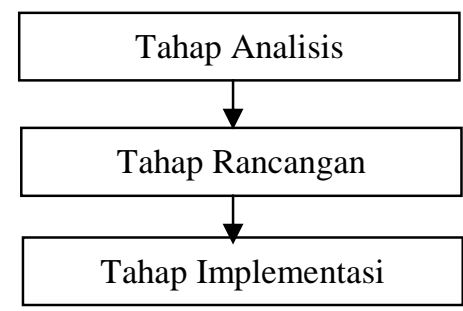

Gambar 1. Metode penelitian

1. Tahap Analisis, pada tahap ini dilakukan survei awal, identifikasi permasalahan terhadap sistem $e$-budgeting pada divisi marketing.

2. Tahap Rancangan Sistem, pada tahap ini dilakukan rancangan sistem menggunakan Diagram UML, pembuatan aplikasi e-budgeting menggunakan bahasa pemrograman php.

3. Tahap Implementasi, pada tahap ini dilakukan implementasi aplikasi e-budgeting.

\section{Hasil dan Pembahasan \\ Rancangan Sistem}

Rancangan sistem aplikasi e-budgeting digambarkan dengan Diagram Unified Modeling Language (UML), UML adalah 'bahasa' pemodelan untuk sistem atau perangkat lunak yang berparadigma "berorientasi objek". Pemodelan (modeling) sesungguhnya digunakan untuk penyederhanaan permasalahan-permasalahan yang kompleks sedemikian rupa sehingga lebih mudah dipelajari dan dipahami. [6] 
- Use Case Diagram
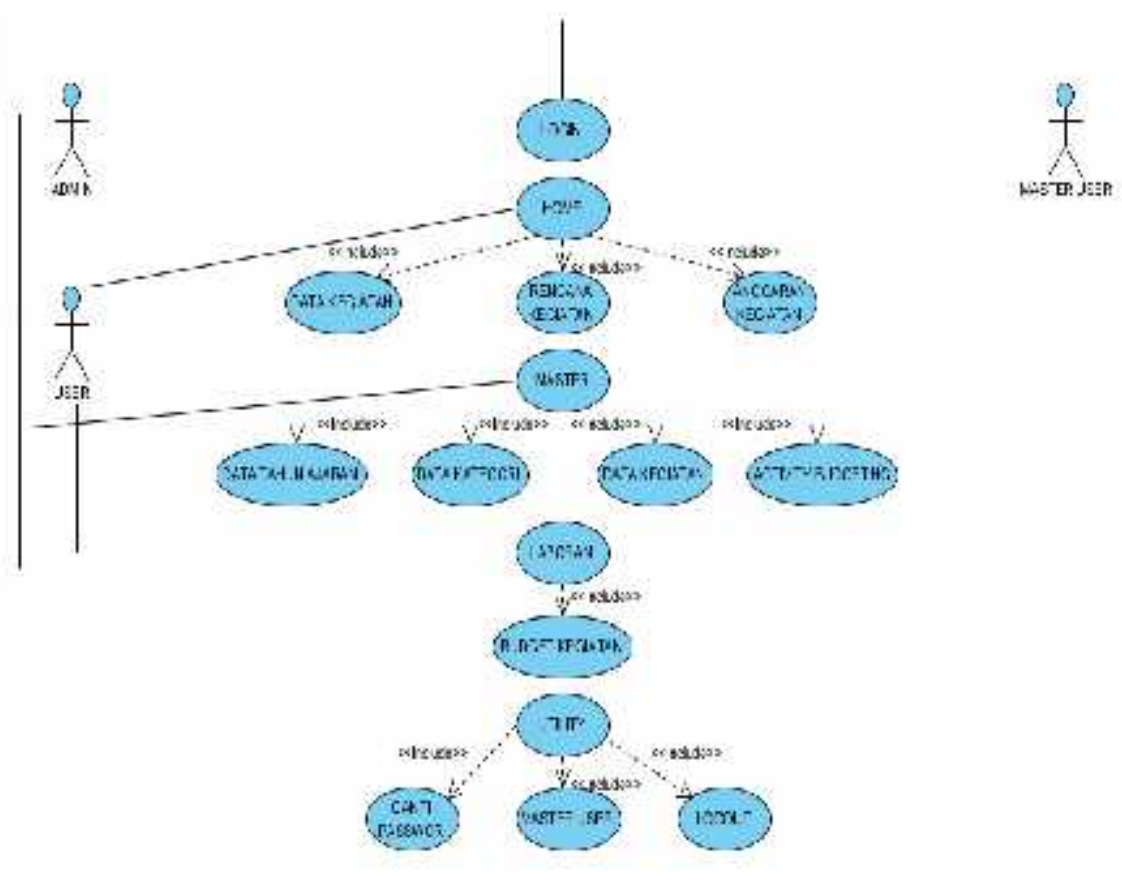

Gambar 2. Rancangan Use Case Diagram

Pada rancangan use case diagram aplikasi e-budgeting (gambar 2), memiliki 3 actor yaitu admin, master user dan user. Serta memiliki 5 use case yaitu login, home, master, laporan, dan utility. Use case home terdiri dari data kegiatan, rencana kegiatan dan anggaran kegiatan. Use case master terdiri dari data tahun ajaran, data kategori, data kegiatan dan activity budgeting. Serta use case utility terdiri dari ganti password, master user dan logout.

- Activity Diagram

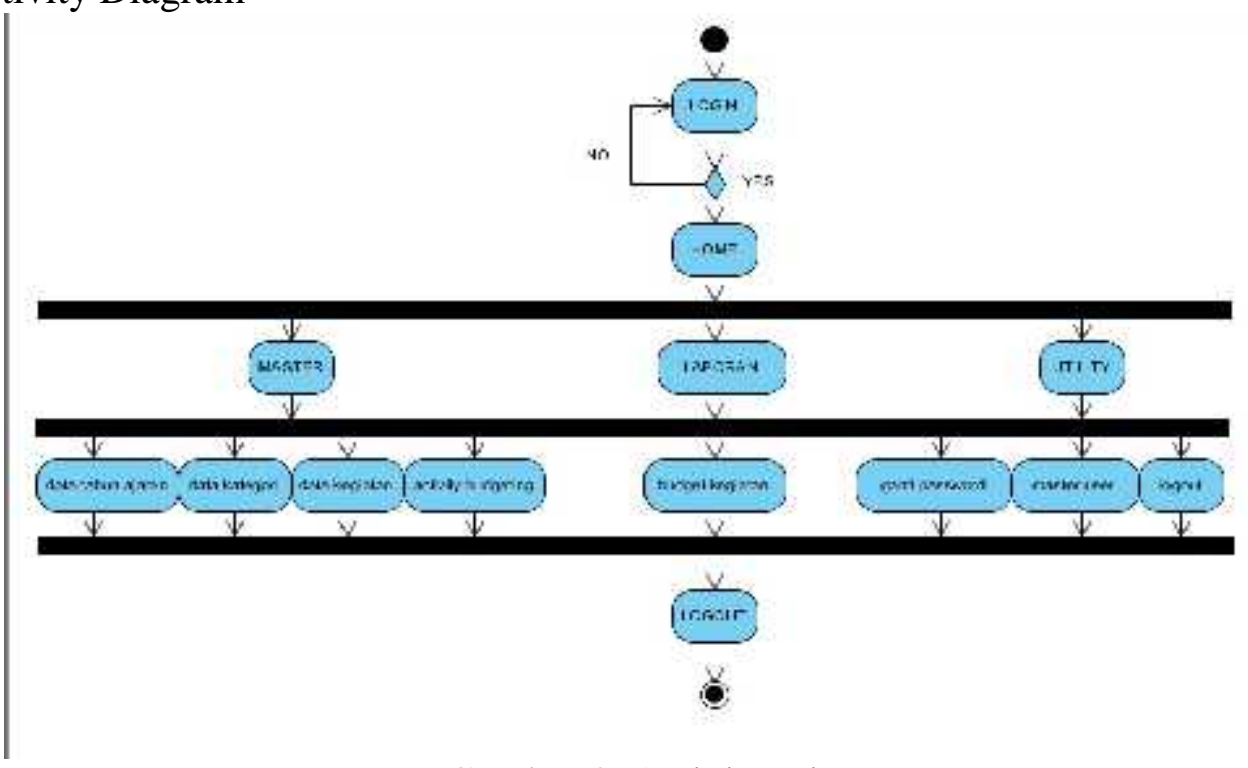

Gambar 3. Activity Diagram

Vol.3 No.2 - Agustus 2017 
Seperti yang terlihat pada gambar 3, terdapat aktivitas-aktivitas yang dilakukan oleh admin, master user dan user. Aktivitas pada menu master yaitu data tahun ajaran, data kategori, data kegiatan dan activity budgeting. Aktivitas pada menu laporan terdiri dari budget kegiatan, serta aktivitas pada menu utility terdiri dari ganti password, master user dan logout.

- Sequence Diagram

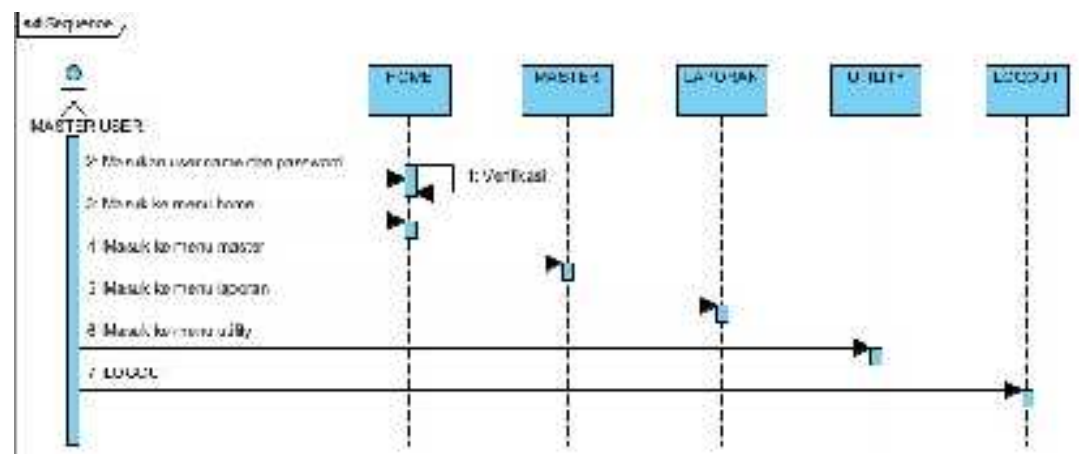

Gambar 4. Sequence Diagram

Pada gambar 4 terdapat beberapa objek yang dirancang pada aplikasi e-budgeting, seperti menu home, menu master, menu laporan, menu utility dan menu logout. Dimana setelah login diverifikasi, master user dapat masuk ke menu home, menu master, menu laporan, menu utility dan logout.

\section{Implementasi}

Berikut ini adalah implementasi dari hasil rancangan aplikasi e-budgeting. Mulai dari halaman login yang tampak pada gambar 5, digunakan untuk mengisi user ID dan password. Jika field diisi dengan benar maka akan masuk ke menu halaman utama. Namun jika salah, maka akan peringatan bahwa user atau password yang diisi salah. 


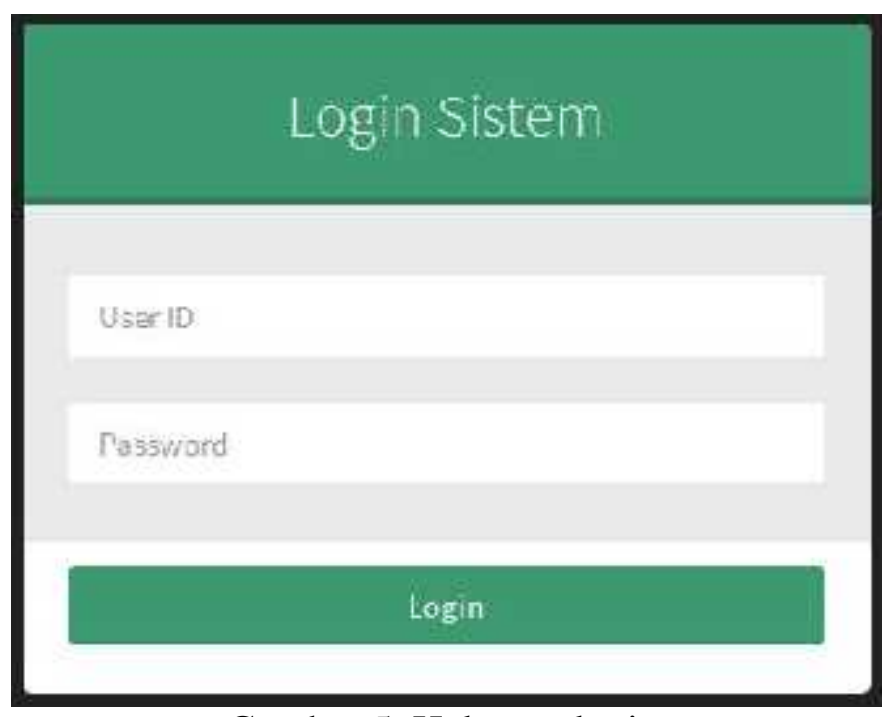

Gambar 5. Halaman login

Pada tampilan home (gambar 6) terdapat menu master, menu laporan dan menu utility. Salah satu sub menu dari menu master adalah data kegiatan. Data-data kegiatan dana promosi diantaranya alumni get student, audio visual, employed get student, family get student, lecture get student, pameran spanduk dan stand, partner get student, student get student dan teacher get student. Pada halaman ini juga terdapat rencana kegiatan dan realisasi kegiatan, serta rencana dana anggaran dan realisasi anggaran dana promosi pada setiap kegiatan.

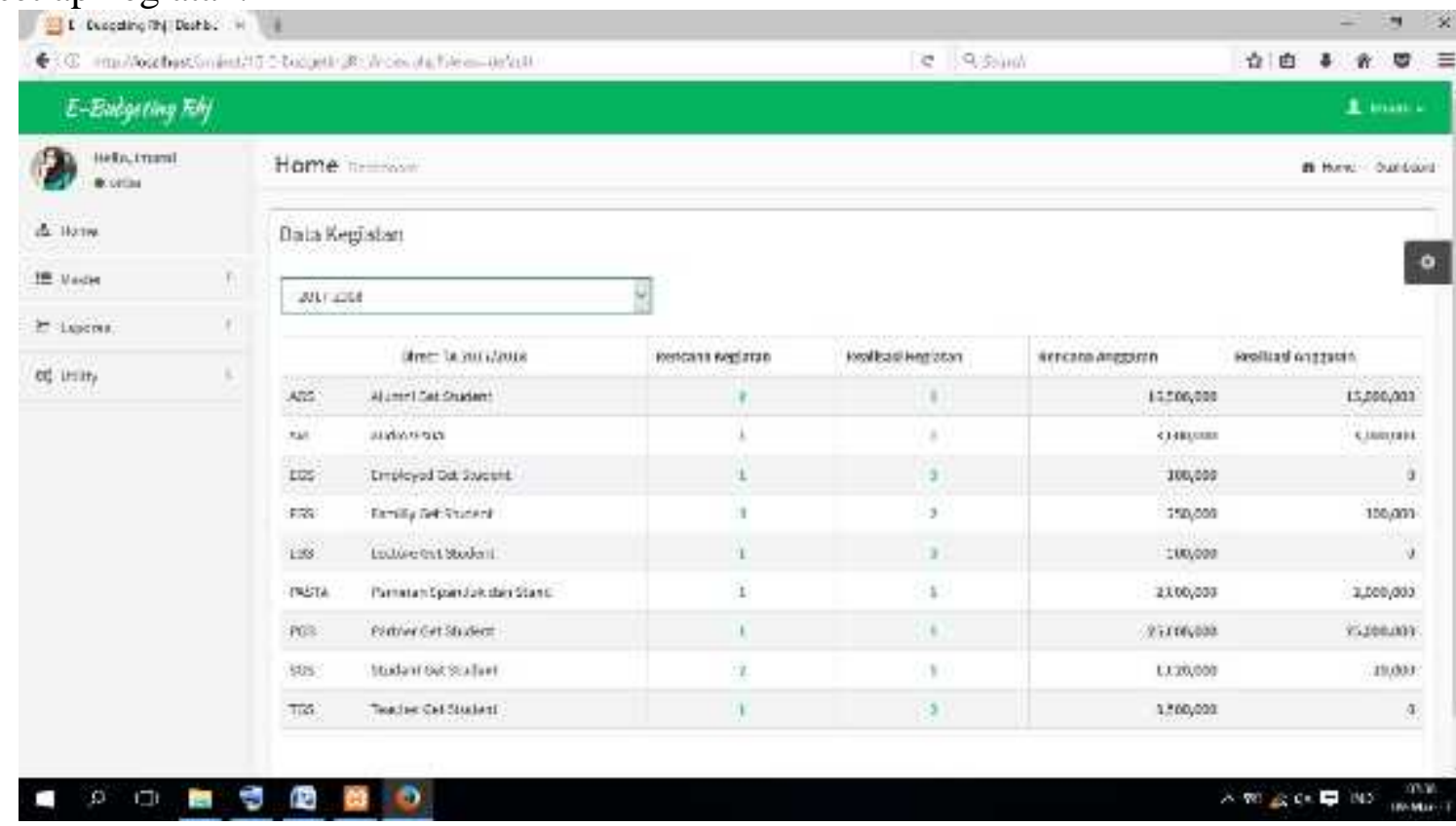

Gambar 6. Tampilan home

Pada Gambar 7 menampilkan sub menu activity budgeting, digunakan untuk menginput data transaksi budget kegiatan. Admin menginput no transaksi, tahun ajaran, tanggal kegiatan, kategori, status dan keterangan. 
ISSN : 2356 - 5195

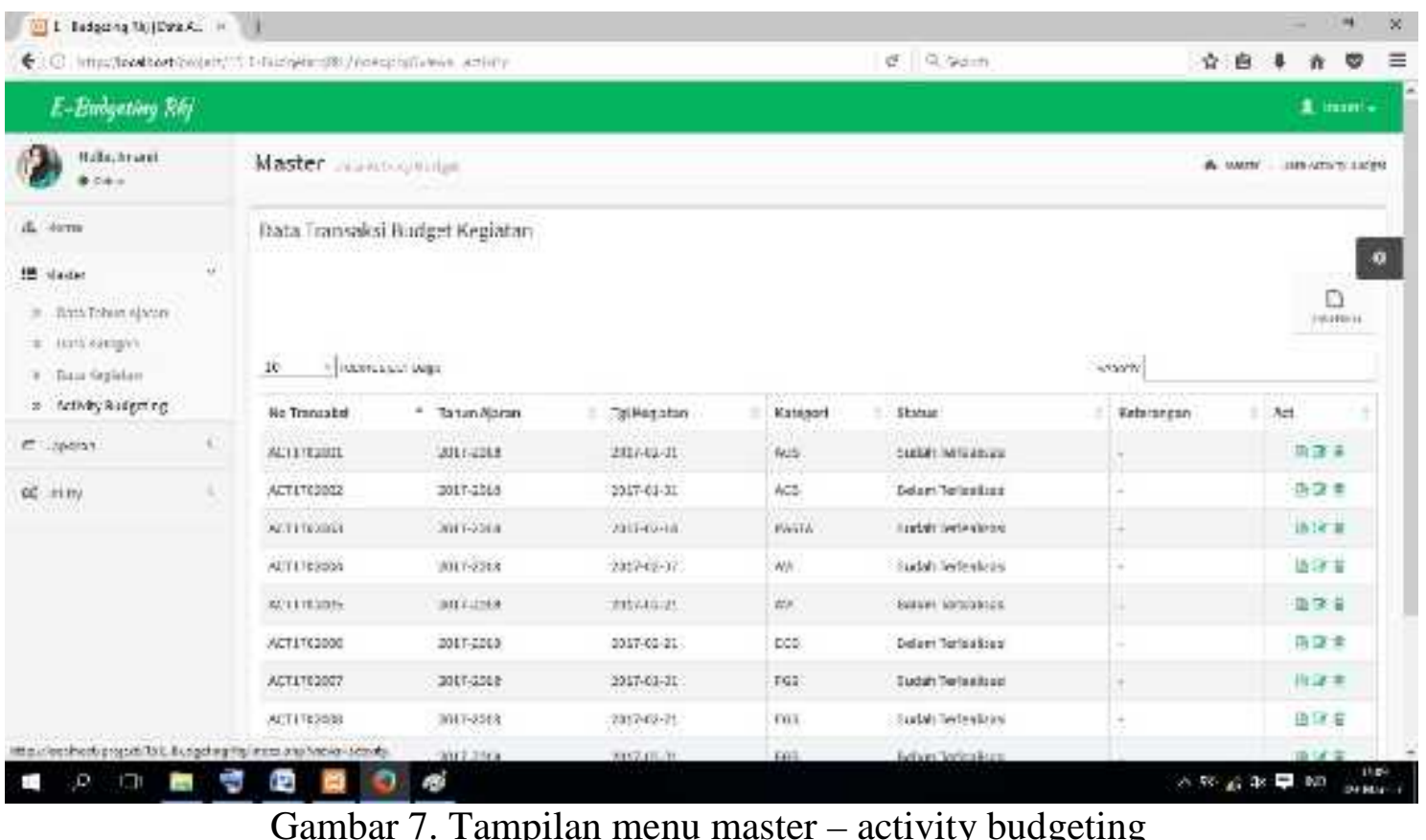

Gambar 7. Tampilan menu master - activity budgeting

Pada menu laporan (gambar 8), admin dapat menampilkan laporan data budgeting kegiatan, dengan memilih jenis kategori kegiatan, status pembayaran dan tanggal transaksi.

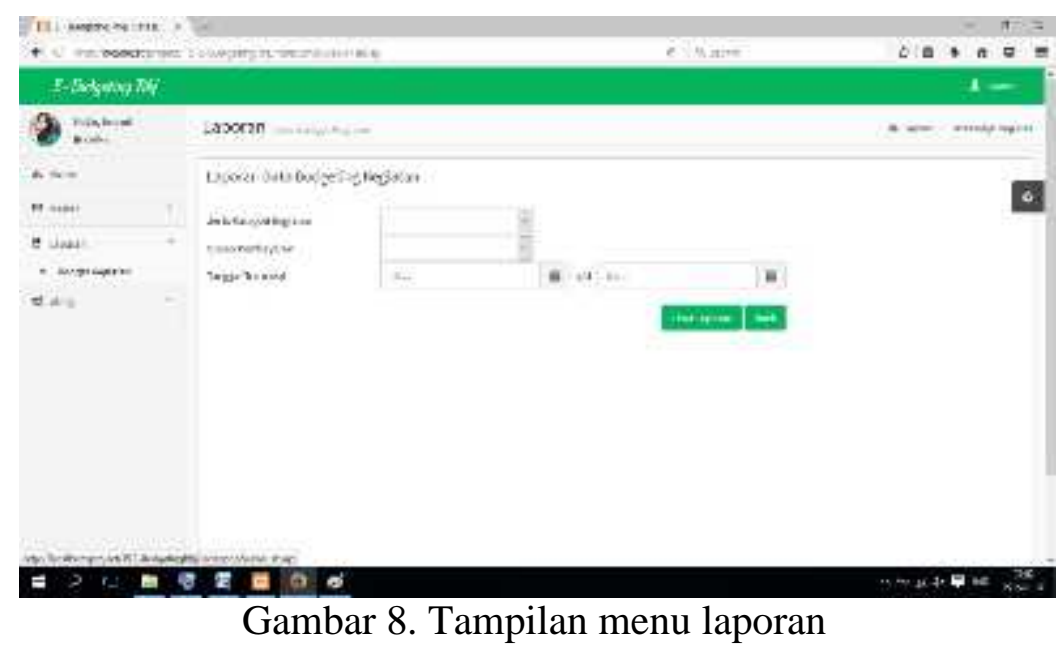

Pada menu utility (gambar 9), admin dapat mengatur hak akses user, dengan cara mengklik data baru dan input user login, nama dan profil. 


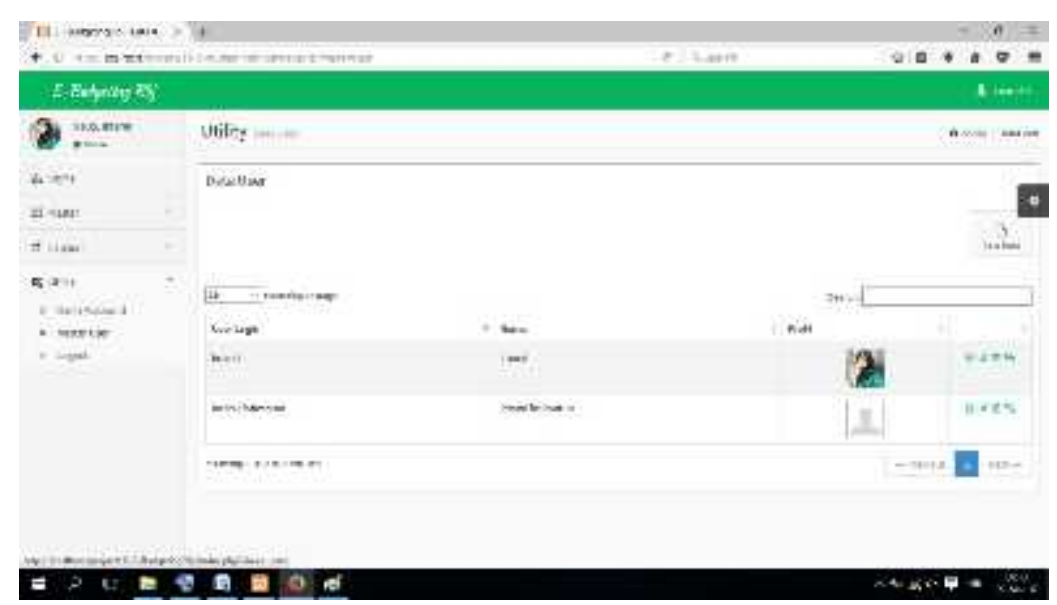

Gambar 9. Sub menu utility

\section{Simpulan}

Rancangan aplikasi e-budgeting dana promosi divisi marketing pada Perguruan Tinggi Raharja dirancang menggunakan metode rekayasa perangkat lunak, yaitu tahap analisis, tahap rancangan sistem dan tahap implementasi. Rancangan sistem digambarkan menggunakan diagram Unified Modeling Language (UML), yang terdiri dari use case diagram, activity diagram dan sequence diagram. Aplikasi yang dibangun berbasis website menggunakan bahasa pemrograman PHP, aplikasi e-budgeting memiliki beberapa menu diantaranya menu home, menu master, menu laporan dan menu utility. Penerapan aplikasi e-budgeting untuk mengelola dana promosi ini dapat meningkatkan efektifitas, efisiensi dan transparansi pengunaan dana.

\section{Daftar Pustaka}

[1] Hidayat, L. 2015. E-Budgeting. https://www.linkedin.com/pulse/e-budgeting-liantohidayat. Diakses tanggal 7 November 2015.

[2] Wahid, F. 2015. E-Budgeting. http://fathulwahid.staff.uii.ac.id/2015/03/. Diakses tanggal 7 November 2015.

[3] Nugroho, A.K. dan Wuryandari, A.I. 2007. Pengembangan E-Budgeting dalam Tata Kelola Pemerintahan Daerah. Konferensi Teknologi Informasi dan Komunikasi untuk Indonesia. 25-26 April 2007, Jakarta, Indonesia. 1-5.

[4] Fanida, E.H. dan Niswah, F. 2015. Government Resource Management System (GRMS): Inovasi Layanan Publik Dalam Pengelolaan Keuangan Daerah Di Pemerintah Kota Surabaya. Jurnal Administrasi Publik. 12 (1): 35-43.

[5] Saadah, B. 2015. Akuntabilitas Dan Transparansi Anggaran Melalui E-Government (Studi Tentang Penganggaran Di Pemerintahan Daerah Kabupaten Blitar). Jurnal Kebijakan dan Manajemen Publik. 3 (2): 1-10.

[6] Nugroho, Adi. 2009. Rekayasa Perangkat Lunak Menggunakan UML \& Java. Yogyakarta: Andi Offset. 